\title{
Scanning electron microscopy of activated carbons prepared from commercial acrylic textile fibres
}

P.J.M. Carrott a, , J.M.V. Nabais a, M.M.L. Ribeiro Carrott a, J.A. Pajares b

aCentro de Química de E' vora, Departamento de Quı́mica, Cole'gio Luı's Anto'nio Verney, Universidade de E 'vora, Rua Romao Ramalho 59, 7000-671 E'vora, Portugal

bInstituto Nacional del Carbo'n, CSIC, Apartado 73, 33080 Oviedo, Spain

Received 12 January 2002; received in revised form 27 March 2002; accepted 28 March 2002

Abstract

Scanning electron microscopy has been used to study the variation in surface texture and dimension during carbonisation and activation of three acrylic textile fibres. The results show that both ordered and disorganised forms of carbon exert a direct influence on the macroscopic structure of the carbon materials. In addition, the results also show that the presence of small amounts of an inorganic additive, namely titanium dioxide, can disrupt the graphene structure and lead to modification of the surface texture and reactivity of the carbon materials. D 2002 Elsevier Science B.V. All rights reserved.

Keywords: Activated carbon; Electron microscopy; PAN

Fuel Processing Technology 77-78 (2002) 381-387 